Litteratur

. Widerøe TE. Kjøtt sett i relasjon til evolusjonen. Tidsskr Nor Legeforen 2016; 136: 1431

2. Bouvard V, Loomis D, Guyton KZ et al. Carcinogenicity of consumption of red and processed meat. Lancet Oncol 2015; 16: 1599-600.

3. Helsedirektoratet. Vegetarisk kosthold. https://helsenorge.no/ kosthold-og-ernaring/vegetarisk-kosthold/naringsrik-vegetarkost (12.9.2016). body weight: a systematic review and meta-analysis of randomized controlled trials. Am J Clin Nutr 2016; 103: 1213-23.

5. Messina V. Nutritional and health benefits of dried beans. Am J Clin Nutr 2014 100 (suppl 1): 437S - 42S

6. Nordic Nutrition Recommendations 2012: Integrating nutrition and physical activity. København: Nordisk ministerråd, 2014. www.norden-ilibrary.org/ social-issues-migration-health/nordic-nutrition-recommendations-2012_nord 2014-002 (19.9.2016).

7. Scientific Report of the 2015 Dietary Guidelines Advisory Committee. Part A Executive Summary. Washington DC: Office of Disease Prevention and Health Promotion, 2015. https://health.gov/dietaryguidelines/2015-scientific-report/ PDFs/02-executive-summary.pdf (19.9.2016).

\section{Re: Hjerteinfarkt, mettet fett og kolesterol}

Kjetil Retterstøl bruker 4S-eksperimentet som bevis på kolesterolhypotesen i sin artikkel om hjerteinfarkt og kolesterol i Tidsskriftet nr. 14-15/2016 (1). Det er imidlertid et problem at ingen av de korrekt utførte statineksperimentene, der man har rapportert den totale dødeligheten, har lyktes like godt som 4S (2). Reduksjonen har i de fleste vært enda mindre enn $2 \%$. I 4S var det dessuten 17 kvinner som døde av hjerteinfarkt i statingruppen, bare $13 \mathrm{i}$ kontrollgruppen. Retterstøl glemmer å fortelle at Merck samtidig med 4S startet det første primærpreventive statineksperimentet, EXCEL (3). Det ble avbrutt etter 48 uker, muligens fordi det var $0,5 \%$ som døde i behandlingsgruppen, mot bare $0,2 \%$ i kontrollgruppen.

Retterstøl mener at dietteksperimentene beviser kolesterolhypotesen, men han nevner bare de to som resulterte i en beskjeden forbedring og ingen av de mange mislykkede eksperimentene. I to av disse økte faktisk dødeligheten med statistisk sikkerhet $(4,5)$. En metaanalyse av kosteksperimentene har dessuten trukket i tvil effekten av å erstatte mettet fett med flerumettet fett i sekundærprofylakse av koronar hjertesykdom (6).

Retterstøl sammenligner statinbehandlingen med bruk av sikkerhetsbelte. Et sikkerhetsbelte er imidlertid ufarlig, det er ikke statinbehandling. Tallrike rapporter fra uavhengige forfattere har pekt på mange alvorlige bivirkninger (7). Den vanligste er muskelsvekkelse og/eller -smerter, hvilket kan hindre trening og mosjon, den beste og ufarligste måte å forebygge hjerte- og karsykdommer på. Og det er mange andre bivirkninger. På internett har legen Kelly Brogan lagt flere lenker til vitenskapelige artikler om statinenes bivirkninger (8). Få kjenner til bivirkningene, fordi de ifølge statinrapportene er sjeldne. En forklaring er at man starter eksperimentene med å teste medisinen på deltagerne, og de som ikke tåler den, utelukkes fra selve eksperimentet.

\section{Paal Røiri}

paal@roiri.no

Paal Røiri (f. 1932) er siviløkonom.

Ingen oppgitte interessekonflikter.

\section{Litteratur}

1. Retterstøl K. Hjerteinfarkt, mettet fett og kolesterol. Tidsskr Nor Legeforen 2016; 136: 1205

2. Kristensen ML, Christensen PM, Hallas J. The effect of statins on average survival in randomised trials, an analysis of end point postponement. BMJ Open 2015; 5: e007118.

3. Bradford RH, Shear CL, Chremos AN et al. Expanded clinical evaluation of lovastatin (EXCEL) study results: III. Efficacy in modifying lipoproteins and implications for managing patients with moderate hypercholesterolemia. Am J Med 1991; $91: 18 S-24 S$
4. Woodhill JM, Palmer AJ, Leelarthaepin B et al. Low fat, Low cholesterol diet in secondary prevention of coronary heart disease. Adv Exp Med Biol 1978; 109 : 317-30.

5. Ramsden CE, Zamora D, Majchrzak-Hong S et al. Re-evaluation of the traditional diet-heart hypothesis: analysis of recovered data from Minnesota Coronary Experiment (1968-73). BMJ 2016; 353: i1246.

6. Schwingshackl L, Hoffmann G. Dietary fatty acids in the secondary prevention of coronary heart disease: a systematic review, meta-analysis and meta-regression. BMJ Open 2014; 4: e004487.

7. Diamond DM, Ravnskov U. How statistical deception created the appearance that statins are safe and effective in primary and secondary prevention of cardiovascular disease. Expert Rev Clin Pharmacol 2015; 8: 201-10.

8. Brogan K, Ji S. Cracking the Cholesterol Myth: How Statins Harm The Body and Mind. www.greenmedinfo.com/blog/cracking-cholesterol-myth-howstatins-harm-body-and-mind $(2.9 .2016)$

\section{K. Retterstøl svarer:}

Pål Røiri sår igjen tvil om statiners effekt ved å vise til Excelstudien (publisert i 1991) og 4S (publisert 1994). Naturligvis kan statiner gi bivirkninger, det må vektes ved tolkning av resultatene. Røiri omtaler videre 4S-studien korrekt med at «den absolutte reduksjonen var imidlertid bare på 3,3\%». Problemet er bare at dette er «ubetydelig» etter hans mening. Hvordan kan han konkludere slik når 74 færre personer i 50-årsalderen døde ved å behandle 2223 personer med statiner i 5,4 år og i tillegg fikk 191 færre personer alvorlig hjertesykdom?

Røiri antyder, utrolig nok, at statiner ikke virker på kvinner, fordi det i 4S-studien døde 17 kvinner av hjerteinfarkt i statingruppen, mot bare 13 i kontrollgruppen. Altså døde fire ekstra kvinner i behandlingsgruppen. Studien kom altså i 1994, og før 4S visste man ikke om statiner reduserte død og hjertesykdom. Det man imidlertid visste var at det pågikk mange studier. Før resultatene fra studiene var kjent, altså prospektivt, skrev man en protokoll om hvordan alle studiene skulle slås sammen for senere å bli undersøkt på forhåndsdefinerte endepunkter (1). Da 174000 personer var inkludert, hvorav $46675 \mathrm{kvinner}$, fant man at $1 \mathrm{mmol} / \mathrm{l}$ senkning i LDL-kolesterol ga $20 \%$ reduksjon i risiko for kardiovaskulære hendelser (2), og det var ingen kjønnsforskjell (3).

Røiri har engasjert seg i «kolesterolhypotesen» i mange år. Jeg har en følelse av at det aldri vil bli mulig å overbevise Røiri om at både sunt kosthold og statiner har sin berettigede plass i forebyggende medisin, og jeg deler derfor Knut Gjesdals oppfatning om at «slik faktafornektelse er provoserende».

\section{Kjetil Retterstø}

kjetil.retterstol@medisin.uio.no

Kjetil Retterstøl (f. 1962) er overlege og professor ved Universitetet i Oslo, Avdeling for ernæringsvitenskap og Oslo universitetssykehus, Lipidklinikken.

Forfatteren oppgir å ha mottatt honorarer fra Sanofi, Mills DA, Amgen, MSD, Chiesi, Takeda, Norsk cardiologisk selskap, Den norske legeforening, Norges forskningsråd.

\section{Litteratur}

1. Protocol for a prospective collaborative overview of all current and planned randomized trials of cholesterol treatment regimens. Cholesterol Treatment Trialists' (CTT) Collaboration. Am J Cardiol 1995; 75: 1130-4.

2. Baigent C, Blackwell L, Emberson J et al; Cholesterol Treatment Trialists' (CTT) Collaboration. Efficacy and safety of more intensive lowering of LDL cholesterol: a meta-analysis of data from 170,000 participants in 26 randomised trials. Lancet 2010; 376: 1670-81.

3. Fulcher J, O'Connell R, Voysey M et al; Cholesterol Treatment Trialists' (CTT) Collaboration. Efficacy and safety of LDL-lowering therapy among men and women: meta-analysis of individual data from 174,000 participants in 27 randomised trials. Lancet 2015; 385: 1397-405. 